\title{
EFFECT OF GALBANIC ACID, A SESQUITERPENE COUMARIN FROM FERULA SZOWITSIANA, AS AN INHIBITOR OF EFFLUX MECHANISM IN RESISTANT CLINICAL ISOLATES OF STAPHYLOCOCCUS AUREUS
}

\author{
Bibi Sedigheh Fazly Bazzaz $^{1} *$, Zahra Memariani ${ }^{2}$, Zahra Khashiarmanesh ${ }^{2}$, Mehrdad Iranshahi $^{1}$, Mahbobeh Naderinasab $^{3}$ \\ ${ }^{1}$ Biotechnology Research Center and School of Pharmacy, Mashhad University of Medical Sciences (MUMS), Mashhad, Iran; \\ ${ }^{2}$ School of Pharmacy, MUMS, Mashhad, Iran; ${ }^{3}$ Microbiology Research Center and School of Medicine, MUMS, Mashhad, Iran
}

Submitted: June 03, 2009; Returned to authors for corrections: August 10, 2009; Approved: February 18, 2010.

\begin{abstract}
Galbanic acid, a sesquiterpene coumarin from Ferula szowitsiana roots, was investigated for its potentiating effect on the antimicrobial activity of antibiotics as well as ethidium bromide, in 6 multidrug resistance (MDR) clinical isolates of Staphylococcus aureus. Galbanic acid had inhibitory effect on none of the isolated bacteria tested (up to $800 \mu \mathrm{g} / \mathrm{ml}$ ). The MIC range of ciprofloxacin, tetracycline and ethidium bromide, against all tested $S$. aureus were 10-80, 10-80 and 4-16 $\mu \mathrm{g} / \mathrm{ml}$, respectively. These were reduced to $\leq 2.5-5,2.5-5$ and $0.5-2 \mu \mathrm{g} / \mathrm{ml}$ in the presence of galbanic acid (300 $\mu \mathrm{g} / \mathrm{ml})$ or verapamil $(100$ $\mu \mathrm{g} / \mathrm{ml})$. The rate of ethidium bromide $(2 \mu \mathrm{g} / \mathrm{ml})$ accumulation in clinical isolates was enhanced with galbanic acid $(300 \mu \mathrm{g} / \mathrm{ml})$. There is also a decrease in loss of ethidium bromide from bacteria in the presence of galbanic acid. Similar results were obtained when verapamil (100 $\mu \mathrm{g} / \mathrm{ml})$ was used as an efflux pump inhibitor. Galbanic acid, like verapamil, a typical inhibitor of efflux pump, reduced the MIC of ethidium bromide and tested antibiotics. Since efflux is the only known reported mechanism for ethidium bromide resistance, the reduction in ethidium bromide MIC and enhanced accumulation as well as decreased efflux of ethidium bromide in the presence of galbanic acid, can be attributed to this efflux inhibitory properties.
\end{abstract}

Key words: Efflux pump inhibitor, Ferula szowitsiana, Galbanic acid, Staphylococcus aureus

\section{INTRODUCTION}

Efflux of antibiotics is a clinically important resistance mechanism for bacteria, often endowing them with multipledrug-resistance (MDR) phenotypes (13). Efflux pumps may be specific for one substrate or may transport various compounds with different structures (17). MDR efflux pumps play an important role in antimicrobial resistance, and by removal of the environmental toxins contribute to the bacterial survival (4). Staphylococcus aureus is a major human pathogen that produces many virulence factors which contribute to its pathogenicity $(6,20)$. This bacterium is a cause for considerable concern, because of its ability to acquire resistance towards the currently used antibacterial agents (19). S. aureus chromosomes encode a range of MDR transporters. Several of these efflux pumps have been identified and demonstrated to cause resistance to various compounds (20). Fluoroquinolone resistance of several clinical isolates of $S$. aureus is provided by the membrane protein NorA encoded in the bacterial chromosome $(12,15)$. Also, over-expression of 
NorB leads to decrease in the susceptibility to fluoroquinolones, tetracycline, disinfectants, and dyes $(17,20)$. NorB, can also facilitate bacterial survival, when overexpressed in a staphylococcal abscess. Also it may contribute to the relative resistance of abscesses to antimicrobial therapy, thus linking bacterial fitness and resistance in vivo (4). It is therefore necessary that new antibiotics, resistance-modifying agents and, more specifically, efflux pumps inhibitors (EPIs) to be identified (19). The reversal of this resistance, via inhibition of drug efflux mechanisms, is a promising research area. In this regard, extensive studies have been performed in order to obtain new effective resistance modifiers from plants (11). The use of these natural bacterial resistance modifiers, including EPIs can facilitate the re-introduction of therapeutically ineffective antibiotics back into clinical use; such as ciprofloxacin, and might even suppress the emergence of MDR strains (19).

There is a report that driportlandin (Fig. 1. B), a sesquiterpene coumarin ether compound, showed a significant effect in inhibiting the efflux pump activity mediated by $\mathrm{p}$ glycoprotein as compared with that of verapamil, a known resistance inhibitor (11). In the present study, we described the effect of galbanic acid, a major plant sesquiterpene coumarin present in Ferula szowitsiana on antimicrobial activity of antibiotics against $S$. aureus (18), as a modulator of antibiotic resistance on clinical isolates of $S$. aureus, and its possible inhibitory effect on MDR pumps.

\section{MATERIALS AND METHODS}

\section{Materials and bacterial strains}

Galbanic acid has been previously isolated and characterized by our group from the roots of Ferula szowitsiana DC., a plant of Apiaceae family (Fig. 1. A) (8). This plant was identified by a member of Herbarium of Faculty of Sciences, University of Tehran, Tehran, Iran. Verapamil and ethidium bromide $(10 \mathrm{mg} / \mathrm{ml}$ solution) were obtained from Recordati (Italy), and Sina Gen (Iran) respectively.
Six isolates of $S$. aureus were received from University Hospital of Imam Reza, in Mashhad, Iran, as multidrug resistant isolates (resistant to cloxacillin, oxacillin, penicillin, erythromycin, chloramfenicol, ampicillin, ciprofloxacin, gentamicin, and tetracycline, sensitive to vancomycin, resistant to cefotaxime and intermediate to ceftazidime). They were subjected again to disk diffusion method for confirmation of their resistance. S. aureus ATCC 6538P (American Type Culture Collection) was used as a control. The used antibiotic disks were methicillin $(30 \mu \mathrm{g} / \mathrm{ml})$, ciprofloxacin $(5 \mu \mathrm{g} / \mathrm{ml})$ and tetracycline $(30 \mu \mathrm{g} / \mathrm{ml})$ [Pad Tan Teb, Iran].

A

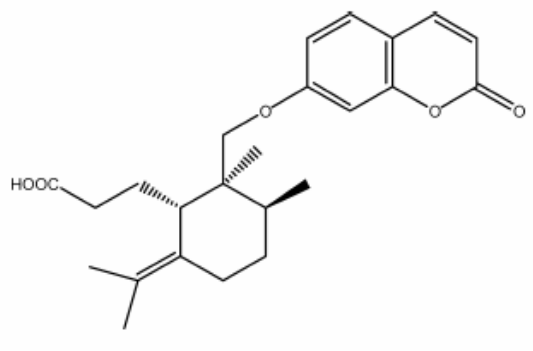

B

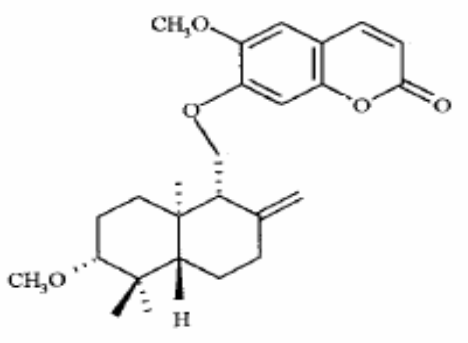

Figure 1. Chemical structure of galbanic acid (A), driportlandin (B)

\section{Susceptibility testing}

MICs of ciprofloxacin (Temad, Iran), tetracycline (Ningxia Qiyuan, China), ethidium bromide and galbanic acid, were determined by macrodilution technique according to the NCCLS guidelines (14), using S. aureus ATCC 6538P as the control strain. In two fold broth dilution method, Muller Hinton Broth (MHB) (Difco, USA), with an inoculum size of approximately $10^{6} \mathrm{CFU} / \mathrm{ml}$, was supplemented with serial 
concentrations of either antibiotics $(2.5-80 \mu \mathrm{g} / \mathrm{ml})$, ethidium bromide $(0.5-16 \mu \mathrm{g} / \mathrm{ml})$, or galbanic acid $(25-800 \mu \mathrm{g} / \mathrm{ml}$, dissolved in dimethyl sulfoxide [DMSO] at final concentration of $1-2 \% \mathrm{v} / \mathrm{v}$ DMSO, with no antibacterial effect on its own). Plates were incubated at $37^{\circ} \mathrm{C}$ for $18 \mathrm{~h}$.

\section{Potentiation of antibiotic activity by galbanic acid}

Potentiation studies were performed by a broth checkerboard method (5). Final bacterial inoculum size in each well was $10^{6} \mathrm{CFU} / \mathrm{ml}$. Galbanic acid was tested at serial two fold sub-MIC concentrations (37.5-300 $\mu \mathrm{g} / \mathrm{ml})$, in combination with either antibiotics $(2.5-80 \mu \mathrm{g} / \mathrm{ml})$ or ethidium bromide $(0.5-16 \mu \mathrm{g} / \mathrm{ml})$. The plates were incubated at $37^{\circ} \mathrm{C}$ for $18 \mathrm{~h}$. As the positive control, verapamil, a known resistance inhibitor was tested in the same manner at serial two fold dilutions (12.5- $100 \mu \mathrm{g} / \mathrm{ml})$.

\section{Accumulation and efflux of ethidium bromide}

Measurement of the level of ethidium bromide accumulation and efflux in 6 clinical multidrug resistant isolates of $S$. aureus and $S$. aureus ATCC 6538P was based on previously described method $(3,15,16)$. Briefly, for measurement of the level of accumulation, bacterial suspension with an optical density of 0.2 at $550 \mathrm{~nm}$ was prepared in uptake buffer (NaCl, 110 mM; KCl, 7 mM; NH4Cl, 5 mM; Na2HPO4, $0.4 \mathrm{mM}$; Tris base, $52 \mathrm{mM}$; glucose $0.2 \%$ adjusted to $\mathrm{pH} 7.5$ with $\mathrm{HCl}$ ) and was then exposed to ethidium bromide at a concentration of $2 \mu \mathrm{g} / \mathrm{ml}$. The increase in fluorescence as ethidium bromide entered the cells was recorded fluorometrically with Shimadzu RF- 540 spectrofluorimeter $(\lambda \mathrm{em}=600 \mathrm{~nm}, \lambda \mathrm{ex}=530 \mathrm{~nm})$ at room temperature. The effect of verapamil and galbanic acid on the level of accumulation was determined in a similar way, after addition of either verapamil $(100 \mu \mathrm{g} / \mathrm{ml})$ or galbanic acid $(300 \mu \mathrm{g} / \mathrm{ml})$ to the uptake buffer. To determine ethidium bromide loss, bacterial suspension was exposed to ethidium bromide $(2 \mu \mathrm{g} / \mathrm{ml})$ for 30 $\min$ at $37^{\circ} \mathrm{C}$. The cells were then pelleted by centrifugation and re-suspended in fresh uptake buffer. This process was repeated again in the presence of either verapamil $(100 \mu \mathrm{g} / \mathrm{ml})$ or galbanic acid $(300 \mu \mathrm{g} / \mathrm{ml})$. The loss of ethidium bromide from the cells was measured as a decrease in fluorescence.

\section{RESULTS}

\section{Susceptibility testing}

Galbanic acid had no inhibitory effect on the bacterial isolates tested (up to $800 \mu \mathrm{g} / \mathrm{ml}$ ). The MICs of ciprofloxacin, tetracycline and ethidium bromide, against S. aureus were 1080, 10-80 and 4-16 $\mu \mathrm{g} / \mathrm{ml}$, respectively. The MEC (minimum effective concentration) for inhibition of ethidium bromide efflux was defined as the lowest amount of either galbanic acid (300 $\mu \mathrm{g} / \mathrm{ml})$ or verapamil $(100 \mu \mathrm{g} / \mathrm{ml})$ which produced the maximum reduction in the MIC. The MICs of ciprofloxacin, tetracycline and ethidium bromide were reduced to less than 2.5-5, 2.5-5 and 0.5-2 $\mu \mathrm{g} / \mathrm{ml}$, respectively, in the presence of either galbanic acid $(300 \mu \mathrm{g} / \mathrm{ml})$ or verapamil $(100 \mu \mathrm{g} / \mathrm{ml})$ (Table 1).

\section{Accumulation and efflux of ethidium bromide}

Figure 2 compares the levels of ethidium bromide accumulation in $S$. aureus ATCC 6538P and isolates of $S$. aureus. As shown in Fig. 2, the rate and amount of accumulation in isolates of $S$. aureus was slower and lower than S. aureus ATCC 6538P. Fig. 3 compares the efflux of ethidium bromide in $S$. aureus ATCC 6538P and clinical isolates of $S$. aureus. The rate of ethidium bromide loss from isolates of $S$. aureus is higher than that of $S$. aureus ATCC 6538P. The rate of ethidium bromide $(2 \mu \mathrm{g} / \mathrm{ml})$ accumulation in clinical isolates was enhanced with galbanic acid (300 $\mu \mathrm{g} / \mathrm{ml}$ ) (Fig. 2). A decrease in loss of ethidium bromide from bacteria was observed in the presence of galbanic acid (Fig. 3). Similar results were obtained when verapamil $(100 \mu \mathrm{g} / \mathrm{ml})$ was used as an efflux pump inhibitor. 
Table 1. Effect of verapamil (efflux pump- inhibitor) and galbanic acid on susceptibility of S. aureus to ciprofloxacin and tetracycline as well as ethidium bromide.

\begin{tabular}{cccc}
\hline & \multicolumn{2}{c}{ MIC $(\boldsymbol{\mu g} / \mathbf{m l})$ of } & \\
\hline Isolated $\boldsymbol{S}$. aureus & ciprofloxacin $(\boldsymbol{\mu g} / \mathbf{m l})$ & $\begin{array}{c}\text { ciprofloxacin+galbanic } \\
\text { acid }(\mathbf{3 0 0} \boldsymbol{\mu g} / \mathbf{m l})\end{array}$ & $\begin{array}{c}\text { ciprofloxacin+verapamil } \\
(\mathbf{1 0 0} \boldsymbol{\mu g} / \mathbf{m l})\end{array}$ \\
\hline 1 & 40 & 5 & $\leq 2.5$ \\
2 & 10 & $\leq 2.5$ & $\leq 2.5$ \\
3 & 80 & $\leq 2.5$ & $\leq 2.5$ \\
4 & 40 & $\leq 2.5$ & $\leq 2.5$ \\
5 & 20 & $\leq 2.5$ & 5 \\
6 & 5 & $\leq 2.5$ & $\leq 2.5$ \\
S. aureus & 5 & $\leq 2.5$ & $\leq 2.5$
\end{tabular}

\begin{tabular}{|c|c|c|c|}
\hline Isolated $S$. aureus & tetracycline $(\mu \mathrm{g} / \mathrm{ml})$ & $\begin{array}{l}\text { tetracycline+galbanic acid } \\
(300 \mu \mathrm{g} / \mathrm{ml})\end{array}$ & $\begin{array}{l}\text { tetracycline+verapamil } \\
(100 \mu \mathrm{g} / \mathrm{ml})\end{array}$ \\
\hline 1 & 80 & $\leq 2.5$ & $\leq 2.5$ \\
\hline 2 & 40 & 5 & 5 \\
\hline 3 & 40 & $\leq 2.5$ & $\leq 2.5$ \\
\hline 4 & 10 & $\leq 2.5$ & $\leq 2.5$ \\
\hline 5 & 40 & 5 & $\leq 2.5$ \\
\hline 6 & 80 & 5 & $\leq 2.5$ \\
\hline $\begin{array}{c}\text { S. aureus } \\
\text { ATCC } 6538 \mathrm{P}\end{array}$ & $\leq 2.5$ & $\leq 2.5$ & $\leq 2.5$ \\
\hline Isolated $S$. aureus & ethidiumbromide $(\mu \mathrm{g} / \mathrm{ml})$ & $\begin{array}{c}\text { ethidium bromide+ } \\
\text { galbanic acid }(300 \mu \mathrm{g} / \mathrm{ml})\end{array}$ & $\begin{array}{l}\text { ethidiumbromide+verapamil } \\
(100 \mu \mathrm{g} / \mathrm{ml})\end{array}$ \\
\hline 1 & 8 & 2 & 2 \\
\hline 2 & 4 & 1 & 2 \\
\hline 3 & 16 & $\leq 0.5$ & $\leq 0.5$ \\
\hline 4 & 8 & $\leq 0.5$ & $\leq 0.5$ \\
\hline 5 & 8 & $\leq 0.5$ & $\leq 0.5$ \\
\hline 6 & 2 & $\leq 0.5$ & $\leq 0.5$ \\
\hline $\begin{array}{c}\text { S. aureus } \\
\text { ATCC } 6538 \mathrm{P}\end{array}$ & 1 & $\leq 1$ & $\leq 1$ \\
\hline
\end{tabular}

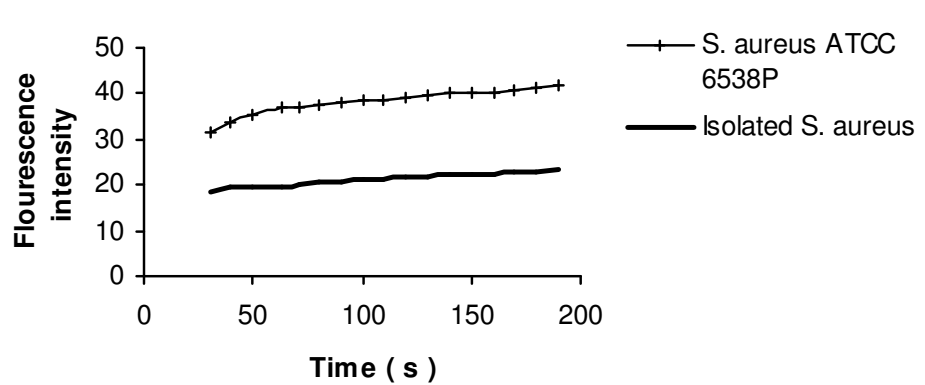

A

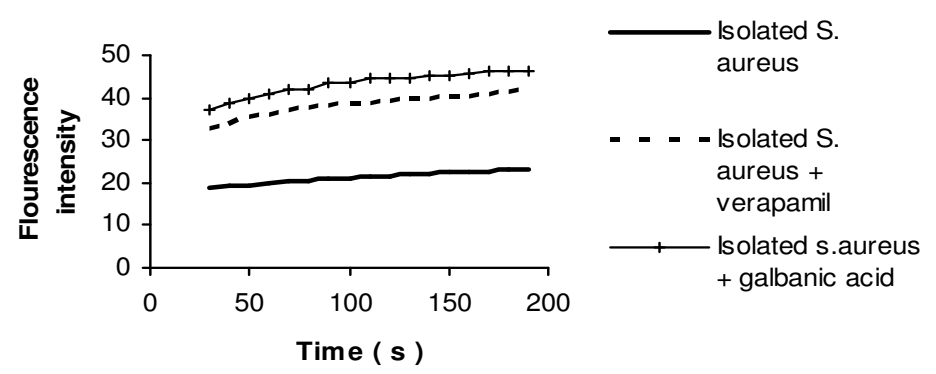

Figure 2. The levels of accumulation of ethidium bromide in $S$. aureus ATCC 6538P and clinical isolates of $S$. aureus, alone or in the presence of galbanic acid or verapamil

A: Accumulation of ethidium bromide by the $S$. aureus ATCC 6538P, and clinical isolates. Data from time 0 to 30 second was not shown. B: Accumulation of ethidium bromide by the clinical isolates of $S$. aureus, alone and in the presence of galbanic acid or verapamil. Data from time 0 to 30 second was not shown.

Each point is the mean of at least three experiments. Data for clinical isolates are the mean of all 6 isolates. 


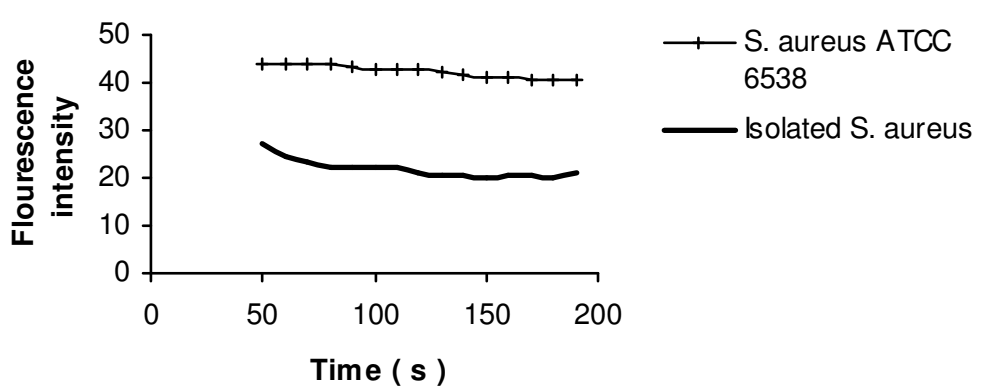

A

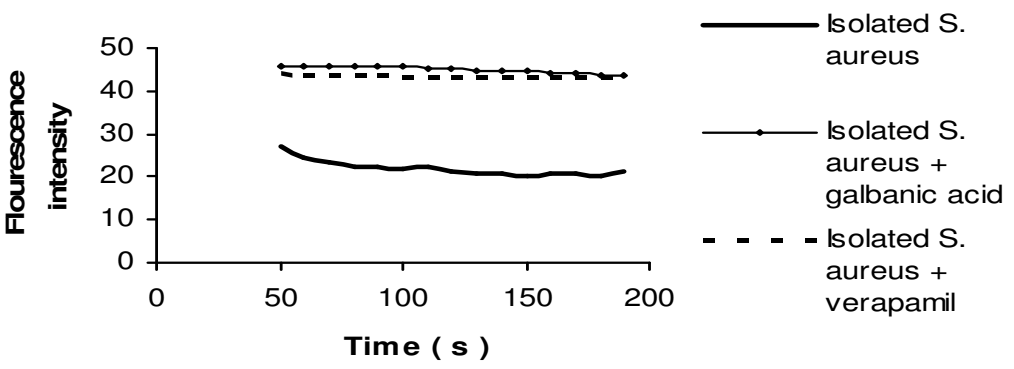

B

\section{DISCUSSION}

The rapid spread of bacteria expressing MDR has necessitated the research and discovery of new antibacterial and resistance-modifying agents (19). A search for compounds that interact with efflux pump proteins and can restore antimicrobial susceptibility has been ongoing for over a decade, initially focusing on Gram-positive bacteria, especially $S$. aureus. Several efflux pump genes are present on the genome of this bacterium, such as NorA and NorB of which NorA confers MDR to chloramphenicol, dyes, fluoroquinolones, antiseptics and disinfectants (17). Overexpression of NorB confers decreased susceptibility to tetracycline, fluoroquinolones, disinfectants, and dyes (17). There are numerous potentially beneficial consequences of inhibition of efflux pumps such as improving the clinical performance of various antibiotics, and several research laboratories and pharmaceutical companies have initiated programs to discover and develop compounds with efflux
Figure 3. The efflux of ethidium bromide from $S$. aureus ATCC 6538P and clinical isolates of $S$. aureus, alone or in the presence of galbanic acid or verapamil

A: Efflux of ethidium bromide from the S. aureus ATCC 6538P, and clinical isolates. Data from time 0 to 50 second was not shown.

B: Efflux of ethidium bromide from clinical isolates $S$. aureus, alone and in presence of galbanic acid or verapamil. Data from time 0 to 50 second was not shown.

Each point is the mean of at least three experiments. Data for clinical isolates are the mean of all 6 isolates. pump inhibitory action (10).These findings suggest that plants could provide a rich source of MDR efflux pump inhibitors and restore the activity of MDR efflux pump substrates.

There is evidence on inhibition of p-glycoprotein of mammalians cells by a sesquiterpene coumarin compound, similar to positive control, verapamil (11). While there is limited structural homology between bacterial and mammalian efflux systems, there is significant substrate overlap (16). Therefore, it is not surprising that many mammalian MDR inhibitors, also effect bacterial efflux $(1,2,7,13,16)$. In this study, galbanic acid -a sesquiterpene coumarin from $F$. szowitsiana- acted as a potentiator of ciprofloxacin and tetracycline activity against 6 resistant clinical isolates of $S$. aureus, with the results similar to verapamil (an efflux pump inhibitor). There was also a decrease in MIC of ethidium bromide in the presence of either verapamil or galbanic acid (at concentrations with no inhibitory effect) (Table 1). Ethidium bromide is a substrate for many Gram-positive multidrug resistance pumps, including NorA or $\operatorname{NorB}(9,20)$. To validate 
the presence of efflux mechanism, the use of a mutant overexpressing the efflux pumps is necessary. Since efflux is the only known mechanism for ethidium bromide resistance (9), the reversal of its MIC for the clinical isolates of $S$. aureus, in the presence of verapamil or galbanic acid, could be an indication of the efflux mechanisms of resistance and the role of galbanic acid as an efflux inhibitor. The efficiency of the efflux pumps, for which the ethidium bromide is a substrate, can be assessed fluorometrically by the loss of fluorescence over time from cells loaded with ethidium bromide $(7,9)$. The increased loss and decreased accumulation of ethidium bromide shown in clinical isolates (Figs 2A and 3A), suggest the presence of efflux mechanism of resistance. There was a difference in the amount of ethidium bromide between isolated S. aureus and isolated S. aureus + galbanic acid or verapamil at $50 \mathrm{~s}$ (Figs 2B and 3B). This shows that in the presence of verapamil or galbanic acid (at MEC) there was an increase in the level of ethidium bromide accumulation and a decrease in loss of ethidium bromide in clinical isolates. This could suggest that galbanic acid inhibits the efflux of ethidium bromide in the same manner as verapamil does. Further work is required to either establish the genetic basis of efflux pump resistance in clinical isolates used or to work on isolates with overproduction of efflux pumps.

\section{ACKNOWLEDGMENTS}

This work was supported financially by the Vice Chancellor for Research of Mashhad University of Medical Sciences, Mashhad, Iran with approval number of 86538.

\section{REFERENCES}

1. Aeschlimann, J.R.; Dresser, L.D.; Kaatz, G.W.; Rybak, M.J. (1999). Effects of NorA inhibitors on in vitro antibacterial activities and postantibiotic effects of levofloxacin, ciprofloxacin, and norfloxacin in genetically related strains of Staphylococcus aureus. Antimicrob. Agents Chemother. 43, 335-340.

2. Bambeke, F.V.; Balzi, E.; Tulkens, P.M. (2000). Antibiotic efflux pumps. Biochem. Pharmacol. 60, 457-470.
3. Brendwald, N.P.; Gill, M.J.; Wise, R. (1998). Prevalence of a putative efflux mechanism among fluoroquinolone resistant clinical isolates of Streptococcus pneumoniae. Antimicrob. Agents Chemother. 42, 20322035.

4. Ding, Y.; Onodera, Y,; Lee, J.C.; Hooper, D.C. (2008). NorB an efflux pump in Staphylococcus aureus strain MW2, contributes to bacterial fitness in abscesses. J. Bacteriol. 190, 7123-7129.

5. Eliopoulus, G.M.; Mollering, R.C.J. (1996). Antimicrobial combinations. In: Lorian, V. (ed). Antibiotics in Laboratory Medicine. The Williams and Wilkins Co. Baltimore, Md, p. 330-396.

6. Gemmell, C.G.; Goutcher, S.C.; Reid, R.; Sturrock, R.D. (1997). Role of certain virulence factors in a murine model of Staphylococcus aureus arthritis. J. Medical Microbiol. 46, 208-213

7. Gibbons, S.; Oluwatuyi, M.; Kaatz, G.W. (2003). A novel inhibitor of multidrug efflux pumps in Staphylococcus aureus. J. Antimicrob. Chemother. 51, 13-17.

8. Iranshahi, M.; Arfa, P.; Ramezani, M.; Jaafari, M.R.; Sadeghian, H.; Bassarello, C.; Piacente, S.; Pizza, C. (2007). Sesquiterpene coumarins from Ferula szowitsiana and in vitro antileishmanial activity of 7prenyloxycoumarins against promastigotes. Phytochemistry, 68, 554-61.

9. Khan, I.A.; Mirza, Z.M.; Kumar, A.; Verma, V.; Qazi, G.N. (2006). Piperine, a phytochemical potentiator of ciprofloxacin against Staphylococcus aureus. Antimicrob. Agents Chemother, 50, 810-812.

10. Lomovskaya, O.; Walkis, W. (2001). Inhibition of efflux pumps as a novel approach to combat drug resistance in bacteria. J. Mol. Microbiol. Biotechnol. 3, 225-236.

11. Madureira, A.M.; Molnár, A.; Abreu, P.M.; Molnár, J.; Ferreira, M.J. (2004). A new sesquiterpene-coumarin ether and a new abietane diterpene and their effects as inhibitors of P-glycoprotein. Planta Med. 70, 828-33.

12. Markham, P.N.; Westhaus, E.; Klyachko, K.; Johnson, M.E.; Neyfakh, A.A. (1999). Multiple novel inhibitors of the NorA multidrug transporter of Staphylococcus aureus. Antimicrob. Agents Chemother. 43, 24042408 .

13. Mullin, S.; Mani, N.; Grossman, T.H. (2004). Inhibition of antibiotic efflux in bacteria by the novel multidrug resistance inhibitors biricodar (VX-710) and timcodar (VX-853). Antimicrob. Agents Chemother. 48, 4171-6.

14. National Committee for Clinical Laboratory Standards (2000). Methods for dilution antimicrobial susceptibility tests for bacteria that grow aerobically, 5th ed. Approved standard M7-A5. National Committee for Clinical Laboratory Standards, Wayne, Pa.

15. Neyfakh, A.A.; Borsch, C.M.; Kaatz, G.W. (1992). Fluoroquinolone resistance protein NorA of Staphylococcus aureus is a multidrug efflux transporter. Antimicrob. Agents Chemother. 37, 128-129.

16. Neyfakh, A.A.; Bidnenko, V.F.; Chen, L.B. (1991). Efflux-Mediated Multidrug Resistance in Bacillus Subtilis: Similarities and Dissimilarities with the Mammalian System. National Academic of Sciences. 88, 4781- 
4785.

17. Piddock, L.J. (2006). Clinically relevant chromosomally encoded multidrug resistance efflux pumps in bacteria. Clin. Microbiol. Rev.19, 382-402.

18. Shahverdi, A.R.; Fakhimi, A.; Zarrini, Gh,; Dehghan, Gh.; Iranshahi, M. (2007). Galbanic acid from Ferula szowitsiana enhanced the antibacterial activity of penicillin $\mathrm{G}$ and cephalexin against Staphylococcus aureus.
Biol. Pharmacol. Bull. 30, 1805-1807.

19. Stavri, M.; Piddock, L.J.; Gibbons, S. (2007). Bacterial efflux pumps inhibitors from natural sources. J. Antimicrob. Chemother. 59, 12471260 .

20. Truong-Bolduc, Q.C.; Dunman, P.M.; Strahilevitz, J.; Projan, S.J.; Hooper, D.C. (2005). MgrA is a multiple regulator of two new efflux pumps in Staphylococcus aureus. J. Bacteriol. 187, 2395-24051. 